\title{
Laboreal
}

Volume $3 \mathrm{~N}^{\circ} 2$ | 2007

Trabalho infantil

\section{Elaboração, estruturação e realização de "gestualidade" de trabalho : os gestos na montagem de automóveis e na cofragem de pontes de auto estrada}

Elaboración, estructuración y realización de gestualidad de trabajo : los gestos en el ensamblaje de automóviles y el encofrado de los puentes de autopista Elaboration, structuration et réalisation des gestuelles de travail : les gestes dans l'assemblage automobile, et dans le coffrage des ponts d'autoroute

Elaboration, structuring and realization of work "gesturality" : the gestures in car assembly and in the moulding of highway bridges

\section{Karine Chassaing}

\section{OpenEdition}

Journals

\section{Edição electrónica}

URL: http://journals.openedition.org/laboreal/12624

DOI: 10.4000/laboreal. 12624

ISSN: 1646-5237

\section{Editora}

Universidade do Porto

\section{Refêrencia eletrónica}

Karine Chassaing, «Elaboração, estruturação e realização de "gestualidade" de trabalho : os gestos na montagem de automóveis e na cofragem de pontes de auto estrada », Laboreal [Online], Volume 3 No2 | 2007, posto online no dia 01 dezembro 2007, consultado o 24 setembro 2020. URL : http:// journals.openedition.org/laboreal/12624; DOI : https://doi.org/10.4000/laboreal.12624

Este documento foi criado de forma automática no dia 24 setembro 2020.

\section{(c) (†) 8}

Laboreal está licenciado com uma Licença Creative Commons - Atribuição-NãoComercial 4.0 Internacional. 


\section{Elaboração, estruturação e realização de "gestualidade" de trabalho: os gestos na montagem de automóveis e na cofragem de pontes de auto estrada}

Elaboración, estructuración y realización de gestualidad de trabajo : los gestos en el ensamblaje de automóviles y el encofrado de los puentes de autopista Elaboration, structuration et réalisation des gestuelles de travail : les gestes dans l'assemblage automobile, et dans le coffrage des ponts d'autoroute Elaboration, structuring and realization of work "gesturality" : the gestures in car assembly and in the moulding of highway bridges

Karine Chassaing

\section{REFERÊNCIA}

Chassaing, K. (2006). Elaboration, structuration et réalisation des gestuelles de travail : les gestes dans l'assemblage automobile, et dans le coffrage des ponts d'autoroute. Thèse d'Ergonomie, Paris : Laboratoire d'Ergonomie, CNAM.

\section{NOTA DO EDITOR}

Manuscrito recebido em : Outubro/2007

Aceite após peritagem em : Novembro/2007 


\section{Os gestos no trabalho, uma questão da actualidade}

1 Esta tese tem como principal objectivo evidenciar a organização complexa dos gestos de trabalho que se aprendem a trabalhar. No nosso ponto de vista, esta organização é complexa, porque resulta de uma elaboração ao longo de toda a vida e dos itinerários profissionais; porque ela é estruturada por invariantes operatórios próprios aos gestos; e, por último, porque se põe em prática em contextos de trabalho que a orientam.

2 Escolher este tema para uma pesquisa em ergonomia supõe, à partida, considerar a sua pertinência social. O gesto tem sido estudado há já bastante tempo em fisiologia do trabalho e em ergonomia. O objectivo da nossa introdução é mostrar que há uma verdadeira questão social em torno do gesto, assim como da experiência no gesto. Esta questão merece ser reafirmada porque, de certo modo, o trabalho manual perdeu visibilidade social. As evoluções do trabalho não implicam "perder" o trabalho manual (Volkoff, 2005). A própria existência de uma patologia do gesto, ou seja, as lesões músculo-esqueléticas (LME's) prova-o claramente. Parece então útil reflectir sobre a construção de gestos para pensar a prevenção das LME's. Por seu lado, a evolução demográfica, com as reformas massivas que se prevêem reforçam o interesse de estudar a relação entre experiência e gestos de trabalho sob o ângulo da transmissão dos saberes-fazer.

\section{O gesto de trabalho, complexo e construído}

3 No prolongamento de uma literatura científica de diferentes disciplinas tais como a fisiologia, a neurofisiologia, a psicologia, a ergonomia, compreender e identificar a complexidade dos gestos parece legítimo para afinar a compreensão da sua construção. Para isso, categorizamos esta complexidade segundo quatro características do gesto :

- "o gesto é composto" : com esta expressão, resumimos a ideia de que o gesto necessita de uma actividade sensorial, cognitiva e motora que implica processos de percepção - tomada de decisão -, acção e uma estrutura de coordenação (Berthoz, 1997) ;

- "o gesto é investido" : é intencional e orientado para objectivos diferentes : para o sistema, para si, e para os outros (Gaudart \& Weill-Fassina, 1999) ;

- gesto é situado" : a este nível, lembramos que a actividade de trabalho, objecto de estudo da ergonomia, é uma actividade em situação. Esta constitui uma das condições da actividade, e portanto, dos gestos realizados no trabalho (Daniellou, 1998);

- "o gesto é construído" : por último, e esta é uma temática predominante na nossa tese, sustentamos a ideia de que o gesto é produto de uma história, de um passado e se desenvolve sem cessar. Analisamos o papel da experiência neste desenvolvimento, tendo ao mesmo tempo em conta as margens do sistema que o permitem, mais ou menos (como favorecem, mais ou menos, a realização do próprio gesto). A experiência é aqui encarada como recurso para desenvolver um gesto (Gaudart, 2000). 


\section{Proposta de um modelo centrado sobre a "gestualidade"}

4 As características do gesto supracitadas, dão conta das suas múltiplas dimensões (psicológica, biomecânica, fisiológica, organizacional...). Mas renovamos estas abordagens insistindo na estruturação dos gestos para completar esta ideia de complexidade, e propondo, para este efeito, um modelo centrado no conceito de "gestualidade". Tratar-se-ia de conjuntos estruturados e previamente constituídos. Formam "armaduras", relativamente estáveis a curto prazo, e utilizáveis em diferentes situações. Elaboram-se e renovam-se sob o efeito da experiência. Consideramos a "gestualidade" como um registo de competências específicas, ou seja, características do uso do corpo, intimamente ligadas ao pólo de "si" da actividade profissional. É algo pessoal, nomeadamente porque os usos do corpo são individualizados. A noção de competência, tal como é definida por De Montmollin (1984), é mais geral que a de "gestualidade": as competências não se reportam unicamente aos gestos. Por isso decidimos tratar, na nossa pesquisa, a "gestualidade" para falar destas competências associadas ao corpo e aos gestos no trabalho.

\section{Métodos de análise da "gestualidade"}

5 Analisámos gestos de trabalho em dois domínios de actividade diferentes: o sector automóvel com, por um lado, uma formação para a destreza nas actividades de montagem de motores, e por outro lado, actividades de soldaduras automáticas num atelier de chaparia ; e a engenharia civil, com as actividades de cofragem de pontes de auto-estrada. Estas três situações são diferentes do ponto de vista das margens-demanobra, da variabilidade na situação e do grau de repetitividade dos gestos. Assim, a confrontação destas três situações permite questionar também as relações entre as margens-de-manobra e a experiência gestual, a propósito da elaboração dos gestos e dos métodos a pôr em prática para compreender este desenvolvimento. Insistimos aqui sobre a componente "realizada" do gesto e, portanto, sobre as suas condições de realização, tanto do ponto de vista dos entraves, como dos factores que favorecem este pôr em prática. Conservámos uma linha metodológica comum às três situações, mas foi necessário adaptar estes métodos a cada uma delas. Uma das escolhas consiste em analisar os gestos que se repetem em cada uma das situações para poder estabelecer comparações entre elas. Realizámos montagens de vídeos de um gesto, previamente escolhido no decurso das análises da actividade, para organizar, de seguida, as autoconfrontações individuais com os operadores.

\section{A "gestualidade" : sua elaboração e sua realização em diferentes contextos}

Mostramos que os operadores elaboram princípios de utilização do seu corpo no trabalho, que lhes asseguram uma maior eficiência e eficácia. Estes princípios são os componentes da "gestualidade", são característicos da acção e transferíveis de uma situação para a outra. Eles permitem ao operador preparar o seu gesto, e ajustá-lo à situação do momento. Os princípios de base identificados nas situações de chaparia e de 
engenharia civil traduzem a existência de regras de acções inerentes ao uso do corpo. Eles são de naturezas diferentes. Na situação do sector automóvel, eles são mais relacionados com a saúde, a atenuação e a redução da dor. Por exemplo, com o princípio : "repartir a força no corpo", o operador procura pontos de apoio no corpo para equilibrar a força, fazendo trabalhar todo o corpo. É o caso de um operador que utiliza a sua anca, para além dos seus dois braços, para colocar a pinça de soldadura no seu sítio. Na situação de engenharia civil, estes princípios estão mais relacionados com a utilização de informações sensoriais, cuja diversificação acresce com a experiência da tarefa. Como por exemplo, "escutar a borboleta a cantar", princípio que passa pelo recurso a referências auditivas. Quando o som da porca do parafuso da borboleta que se está a martelar se torna agudo, significa que a porca está suficientemente apertada. Por outro lado, estão relacionados com regras de aç̧ão do tipo "se... então" que permitem gerir a diversidade dos contextos. Por exemplo, se o cimento está muito seco, é preciso, então, forçar mais com a talocha e passar mais vezes para que a superfície fique bonita e direita.

7 A "gestualidade" pertence a uma mesma classe de actividade e não a um dado contexto. A análise da experiência dos operadores permite compreender a sua origem, tomar em consideração o passado do operador, e identificar o papel de situações anteriormente vividas. A "gestualidade" constrói-se a partir de aprendizagens resultantes dessas situações, que categorizamos em quatro origens, segundo os quatro modos de aquisição da experiência :

- a experiência originada pela prática profissional (tanto do ponto de vista da prática actual como do passado) ;

- a experiência originada pela prática extra-profissional ;

- a experiência originada pela prática dos outros ;

- a experiência originada pelo conhecimento de si e dos seus limites.

Os resultados obtidos são fortemente marcados pelos modos de organização que prevalecem neste ou naquele meio profissional. É necessário sublinhar a que preço os operadores conseguem regular a sua actividade nas situações. É nas margensdemanobra que concede a organização do trabalho, que se exprime e se constrói esta experiência gestual, a partir das práticas reflexivas. Na montagem automóvel, a "gestualidade" resiste à estandardização do trabalho. Desafiam-na dois instrumentos prescritores : uma formação para a destreza e fichas de operações standards. Propomos, assim, uma racionalidade alternativa à da estandardização, insistindo sobre a impossível transcrição de gestos em procedimentos estandardizados. Na engenharia civil, mais caracterizada pela forte variabilidade dos contextos, e pela preeminência de uma cultura de ofício, reforçamos mais a estruturação e o desenvolvimento de "gestualidades" num contexto de transmissão de saberes-fazer. Neste caso, a "gestualidade" permite gerir a diversidade do contexto, ao mesmo tempo que se converte num recurso para que ela própria se enriqueça e se transmita. 


\section{Pistas possíveis de acção}

9 Na nossa opinião, os resultados contribuem para propor pistas de transformação e acção em pelo menos três direcções :

- valorizar os saberes-fazer manuais em ofícios pouco qualificados, e num contexto industrial que tende para a racionalização. Tratar-se-ia de enriquecer os argumentos dos ergónomos face aos modelos da estandardização ;

- prevenir as LME's, já que as reflexões sobre a construção dos gestos (ou os entraves a esta construção) ampliariam a gama de acções possíveis sobre a organização do trabalho, as margens-de-manobra potenciais, a rotação nos postos, ou a formação ;

- e, por último, transmitir o saber profissional no trabalho manual : tanto do ponto de vista do reajustamento ao nível da organização do trabalho (por exemplo, tornar possível o pôr em comum as práticas, o desenvolvimento de práticas reflexivas), como do ponto de vista do enriquecimento dos programas de formação.

\section{BIBLIOGRAFIA}

Berthoz, A. (1997). Le sens du mouvement. Ed. Odile Jacob. Paris. 345p.

Daniellou, F. (1998). Une contribution nécessaire au recensement des “ Repères pour affronter les TMS ». In Bourgeois, F. TMS et évolution des conditions de travail. Etudes et Documents. ANACT. 35-46.

Gaudart, C. (2000). Conditions for maintaining ageing operators at work - a case study conducted at an automobile manufacturing plant. Applied Ergonomics, vol. 31, $\mathrm{N}^{\circ}$ 5, pp. 453-462.

Gaudart, C. \& Weill-Fassina, A. (1999). L'évolution des compétences au cours de la vie professionnelle : une approche ergonomique. Formation Emploi, $\mathrm{N}^{\circ} 67$, pp. 47-62.

Montmollin, M. (de) (1984). L'intelligence de la tâche. Eléments d'ergonomie cognitive. Eds Peter lang. Berne.

Volkoff, S. (2005). L'ergonomie et les chiffres de la santé au travail : ressources, tensions et pièges. Toulouse, Éditions Octarès.

\section{AUTOR}

\section{KARINE CHASSAING}

Centre d'Études de l'Emploi / CREAPT 29, Promenade Michel Simon, 93166 Noisy-Le-Grand Cedex karine.chassaing@wanadoo.fr 